\title{
The role of heterogeneity in asthma: a structure-to-function perspective
}

\author{
Justin K. Lui ${ }^{1 *}$ and Kenneth R. Lutchen ${ }^{2}$
}

\begin{abstract}
A number of methods have evolved through the years in probing the dysfunction that impacts mechanics and ventilation in asthma. What has been consistently found is the notion of heterogeneity that is not only captured in the frequency dependence of lung mechanics measurements but also rendered on imaging as patchy diffuse areas of ventilation defects. The degree of heterogeneity has been linked to airway hyperresponsiveness, a hallmark feature of asthma. How these heterogeneous constriction patterns lead to functional impairment in asthma have only been recently explored using computational airway tree models. By synthesizing measurements of lung mechanics and advances in imaging, computational airway tree models serve as a powerful engine to accelerate our understanding of the physiologic changes that occur in asthma. This review will be focused on the current state of investigational work on the role of heterogeneity in asthma, specifically exploring the structural and functional relationships.
\end{abstract}

Keywords: Asthma, Heterogeneity, Ventilation, Lung mechanics, Computational modeling

\section{Introduction}

Asthma is an obstructive lung disease commonly associated with increased airway hyperresponsiveness (AHR) resulting in bronchoconstriction and airway inflammation. When provoked, the airways constrict in a heterogeneous pattern leading to airflow obstruction and impedance of gas transport to and from the lungs. The concept of heterogeneity extends past what occurs structurally to also characterizing both the clinical presentation (or phenotype) [1, 2] and underlying pathogenesis (or endotype) of the disease [3, 4]. Both clinical phenotypes and molecular endotypes are interrelated by genetic factors which continue to play a key role in the development of personalized approaches to the diagnosis and treatment of asthma $[2,5,6]$. Although beyond the scope of this review, studies have provided evidence in the existence of multiple genes associated with lung function in asthma that may lead to the degree of heterogeneous distribution of structural defects and consequent functional defects [7-10]. Our review focuses on the

\footnotetext{
*Correspondence: justin.lui@bmc.org

1 Department of Medicine, University of Massachusetts Medical School,

55 Lake Avenue North, Worcester, MA 01655, USA

Full list of author information is available at the end of the article
}

structure-function consequences of heterogeneous disease not the genetic origins of such. Specifically, we will focus primarily on the various techniques in assessing how heterogeneous changes in lung structure caused by asthma which result in changes to mechanical and ventilation function.

The degree of mechanical dysfunction can be assessed from measurements of flow $\left(Q_{a o}\right)$ and pressure $\left(P_{a 0}\right)$ at the airway opening from which an in-phase (or energy loss) component or lung resistance $\left(R_{L}\right)$ and an out-ofphase (or energy storage) component or lung elastance $\left(E_{L}\right)$ of this relationship can be derived by what is known as the forced oscillation technique (FOT) [11-16]. Through evaluation of the respiratory system response to forced flow, the technique enables a rapid assessment in the degree of frequency dependence of $R_{L}$ and $E_{L}$ which allows inference on the severity of airflow obstruction [17-22] and the degree of bronchodilation after intervention [23-26]. While such methods provide evidence of degree in the heterogeneity of constriction, the ability to visualize ventilation abnormalities due to bronchoconstriction in asthma has been limited until recent advances in imaging. With the advent of hyperpolarized helium-3 magnetic resonance imaging ( $\mathrm{HP}{ }^{3} \mathrm{He} \mathrm{MRI}$ ), there is now a noninvasive method to directly visualize 
areas of ventilated airspaces within the lung [27-36]. While normally ventilated lungs exhibit a homogeneous distribution of signal, obstructive lung diseases such as asthma demonstrate heterogeneously distributed nonventilated areas known as ventilation defects. How these structural changes alter function has only been recently shown through computational modeling approaches of the lung [21, 22, 27, 37-41].

\section{Heterogeneity of lung mechanics}

The forced oscillation technique

First introduced in 1956 by Dubois et al. [13], the FOT is a noninvasive tool for the measurement of the mechanical impedance of the respiratory system. The technique involves delivery of pressure oscillations either around the chest wall inside an enclosed chamber $\left(P_{c w}\right)$ or alternatively at the mouth at the site of airway opening $\left(P_{a 0}\right)$, which is more commonly used. The predefined oscillations were originally within the range of $4-32 \mathrm{~Hz}$ with a fixed limited magnitude to allow for spontaneous breathing. The apparatus generally consists of a loudspeaker to deliver the pressure signal and utilizes a high inertance bias tube placed in parallel to allow for a minimization of energy loss from the pressure oscillations while also providing fresh air to prevent carbon dioxide buildup within the dead space. By measuring flow at the airway opening $\left(Q_{a o}\right)$, the ratio of $P_{c w} / Q_{a o}$ can be used to calculate the transfer impedance of the system $\left(Z_{t r}\right)$. Alternatively, the ratio of $P_{a 0} / Q_{a o}$ can be used to calculate the input impedance of the system $\left(Z_{i n}\right)$-this is often referred to as the impedance of the total respiratory system $\left(Z_{r s}\right)$ with contributions from both the lungs $\left(Z_{L}\right)$ and the chest wall $\left(Z_{c w}\right)$. The corresponding relationship is a complex ratio expressed as a function of oscillation frequency, in radians $(\omega)$, divided into an in-phase resistive component $\left(R_{r s}\right)$ and an out-of-phase reactive component $\left(X_{r s}\right)$ :

$$
Z_{r s}(\omega)=R_{r s}(\omega)+j X_{r s}(\omega)
$$

in which $j$ is defined as $\sqrt{-1}$, an imaginary number. In its individualized components, $R_{r s}$ embodies the dissipative mechanical properties or energy losses of the respiratory system over one cycle at a particular frequency, while $X_{r s}$ embodies the energy storage capacity. To isolate the input impedance of the lungs alone $\left(Z_{L}\right)$, an esophageal balloon catheter is used to measure the intraesophageal pressure $\left(P_{e s}\right)$ which approximates to be the intrapleural pressure $\left(P_{i p}\right)$ from which a transpulmonary pressure $\left(P_{t p}\right)$ can be calculated by the difference between $P_{a o}$ and $P_{e s}$, given as:

$$
Z_{L}(\omega)=\frac{P_{a o}(\omega)-P_{e s}(\omega)}{Q_{a o}(\omega)}
$$

Over the frequency range of $4-32 \mathrm{~Hz}$, however, $R_{r s}$ has been found to be relatively constant with frequency while $X_{r s}$ has been found to increase monotonically with frequency $[12,14]$. These data do not reflect much detail in the why or where or how they become abnormal in diseased states such as asthma. In contrast, lower frequency ranges $(<10 \mathrm{~Hz})$ have been found to be more relevant to mechanical properties with increased sensitivity to structural changes that capture phenomena such as airway wall distensibility [42, 43], tissue viscoelasticity $[44,45]$, smaller parallel time-constant heterogeneity [46], and expiratory flow limitation [47, 48]. Obtaining lung mechanics near spontaneous breathing frequencies becomes challenging as it requires subjects to remain apneic at functional residual capacity (FRC) for extended periods of time while forced oscillations are delivered [49]. A solution to this has been the design of a computer-driven optimal ventilation waveform (OVW) consisting of seven non-sum, non-difference sine waves with frequencies spanning from 0.156 to $8 \mathrm{~Hz}[18,19,50$, 51]. The OVW would ventilate the subject with a normal tidal volume of air per cycle with a linear piston pump while simultaneously delivering forced oscillations at all the target frequencies [50]. The clinical utility of using FOT at lower frequencies is that such data is sensitive to changes in tissue viscoelastic properties as well as the occurrence and impact of heterogeneous airway constriction inclusive of capturing whether there are nearclosures throughout the airway tree $[18,23]$. To quantify these phenomena one can apply inverse modeling to the data, but to better understand how explicit structural changes in a whole lung might impact the data, one can apply forward modeling approaches.

\section{Model approaches to lung mechanics} Inverse modeling

A simple inverse model used to characterize $Z_{r s}$ relating $Q_{a o}$ and $P_{a o}$ of the respiratory system is the single compartment model comprising elements of resistance $\left(R_{r s}\right)$, elastance $\left(E_{r s}\right)$, and inertance $\left(I_{r s}\right)$ in a linear series described below:

$$
Z_{r s}(\omega)=R_{r s}(\omega)+j \omega I_{r s}(\omega)+\frac{E_{r s}(\omega)}{j \omega}
$$

$E_{r s}$, dominant at low frequencies, represents the stiffness of parenchymal tissue and the chest wall. $I_{r s}$, dominant at high frequencies, represents the energy required to move gas within the lungs in response to forced oscillations [12]. The resonant frequency, $\omega_{0}$, in which $X_{r s}$ is zero, can be determined by rearranging Eqs. 1 and 3 to be given as:

$$
\omega_{0}=\sqrt{\frac{E_{r s}(\omega)}{I_{r s}(\omega)}}
$$


Over low frequencies in which $\omega \ll \omega_{0}$, the contribution of $I_{r s}$ approaches zero, and the $X_{r s}$ is essentially determined by $E_{r s}$ which is related in common practice as:

$$
E_{r s}(\omega)=-\omega X(\omega)
$$

The single compartment model is readily applicable to data between 4 and $32 \mathrm{~Hz}$ in healthy and moderate disease but of course provides only three lumped properties averaged over the entire respiratory system with no resolution as to how airways, lung tissue or heterogeneous disease impacts them. When taking data out to higher frequencies $(64-128 \mathrm{~Hz})$ a variant of the six-element lumped model that was initially introduced by Dubois et al. [13] has been suggested in which airway resistance and inertance $\left(R_{a w}, I_{a w}\right)$ are separated from tissue resistance, inertance, and compliance $\left(R_{t i}, I_{t i}, C_{t i}\right)$ by a shunt compliance to represent the compressibility of alveolar gas $\left(C_{g}\right)$ (Fig. 1) [52-54]. However, when applied to human data, this model fails as the data are insufficiently sensitive to a resonant peak associated with gas compression $[55,56]$.

It is now appreciated that one of the most important functional consequences of any lung disease is that it impacts the lungs heterogeneously. For example, when a system of parallel impedance pathways develop heterogeneous constriction the resulting increase in overall $R_{L}$ and $E_{L}$ at typical breathing frequencies is much higher than what would be predicted simply from the average decrease in all airway diameters [19, 22]. To capture the impact of disease on lung tissue and heterogeneous properties one can apply inverse models to data at lower frequencies. A commonly used model is the constant phase model from 0.1 to $4 \mathrm{~Hz}$. The origins of the constant phase model relative to data derived from an alveolar capsule technique was used to explicitly measure parenchymal tissue viscoelasticity $[51,57]$ and partition tissue properties from airway properties within the respiratory system. In normal lungs, $R_{a w}$ was found to remain relatively constant with increasing frequency while $R_{t i}$ was found to decrease in a near-hyperbolic manner [58-61]. Tissue viscoelasticity is best captured with a constant phase model [62] based on a variant of the Horie and Hildebrandt model for stress-relaxation [63-65]. $Z_{L}$ can be divided into its airway $\left(Z_{a w}\right)$ and tissue $\left(Z_{t i}\right)$ components described below [62]:

$$
\begin{aligned}
& Z_{L}(\omega)=Z_{a w}(\omega)+Z_{t i}(\omega) \\
& Z_{a w}(\omega)=R_{a w}(\omega)+j \omega I_{a w}(\omega) \\
& Z_{t i}(\omega)=\frac{G-j H}{\omega^{\alpha}}
\end{aligned}
$$

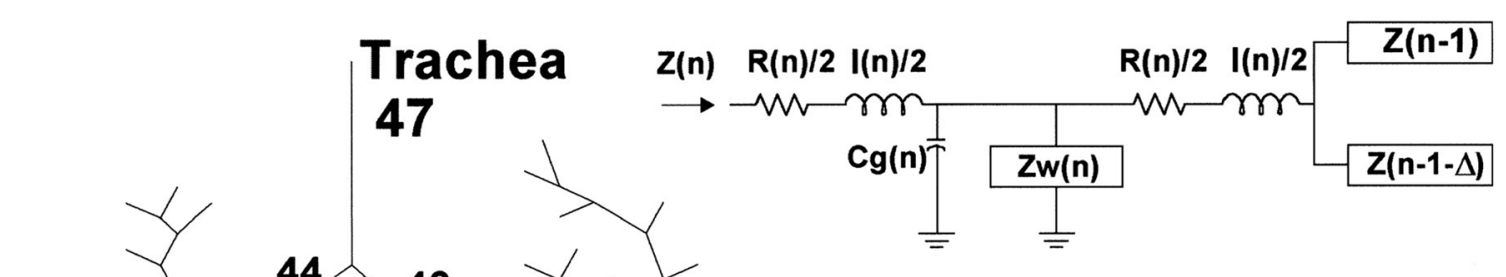

Impedance of a single airway generation

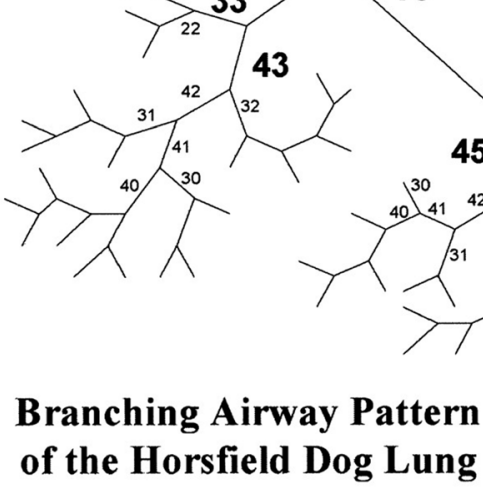

$43^{42}$ 41

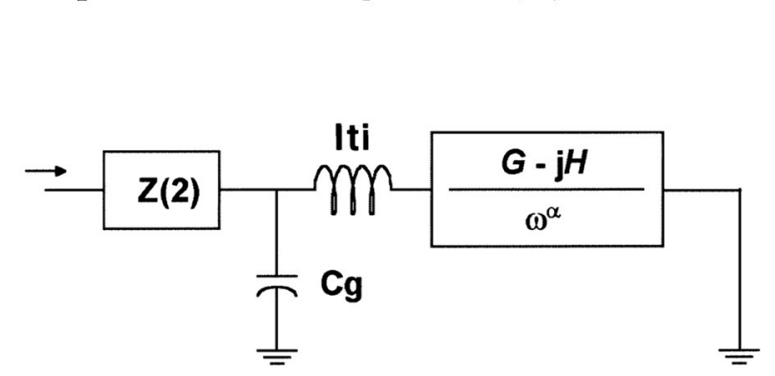

Alveolar Tissue Element

Fig. 1 Schematic of the Horsfield lung model. Individual airways are modeled with a lumped six element model with an alveolar tissue element at the terminal units based on a given order $(n)$ and a recursion index $(\Delta)$. The dog lung model depicted here is comprised of 47 airway orders with a defined length and diameter. Each airway consists of a resistive component (R), an inertial component (I), and as well as a term to account for shunting into gas compression in the tube $(\mathrm{Cg})$ and into nonrigid airway walls $\left(Z_{w}\right)$. The viscoelastic alveolar tissue element is modeled with a tissue damping term $(\mathrm{G})$ coupled to elastance $(\mathrm{H})$ and an inertial tissue component $\left(\mathrm{l}_{\mathrm{t}}\right)$ with a gas compression corresponding to the volume of the alveolus (Cg) (reproduced with permission from [54]) 
In which $G$ is a coefficient reflecting viscous energy dissipation (also known as tissue damping) and $H$ is a coefficient reflecting energy storage (also known as tissue elastance). The parameter, $\alpha$, is related to $G$ and $H$ given as:

$$
\alpha=\frac{2}{\pi} \tan ^{-1}\left(\frac{H}{G}\right)
$$

Constant phase refers to the phase angle between pressure and flow across the lung tissue in which the component $\tan ^{-1}(H / G)$ is constant and independent of frequency. Based on the model, the $R_{t i}$ component of $Z_{t i}$ can be given as:

$$
R_{t i}(\omega)=\frac{G}{\omega^{\alpha}}
$$

To determine the model parameters, a nonlinear gradient search technique can be used by minimization of a performance index, $\Phi$, for the estimation of the "goodness-of-fit" index, $\sigma^{2}$, given as [18]:

$$
\begin{gathered}
\Phi=\sum_{k=1}^{N}\left\{\left[\operatorname{Re}_{d}(k)-\operatorname{Re}_{m}(k)\right]^{2}+\left[\operatorname{Im}_{d}(k)-\operatorname{Im}_{m}(k)\right]^{2}\right\} \\
\sigma^{2}=\frac{\Phi}{2 N-P}
\end{gathered}
$$

where $\operatorname{Re}(k)$ and $\operatorname{Im}(k)$ denote the real and imaginary components of $Z_{L}$ at the $k t h$ frequency, respectively, and the subscripts $d$ and $m$ denote the actual data and model predicted values, respectively. $N$ is the number of frequencies, and $P$ is the number of free parameters in the model. Applying the parameters of this model, $R_{L}$ can be partitioned into its airway (i.e., central) component, $R_{a w}$ and tissue (i.e., peripheral) components, $R_{t i}$. Interestingly, $R_{t i}$ has been found to constitute a substantial component of $R_{L}$ in healthy subjects ( 40\%) while $R_{a w}$ has been found to constitute a substantial component of $R_{L}$ in asthmatic subjects $(>70 \%)[18,23]$. The major limitation of using the constant phase model is that when airway constriction is heterogeneous it creates amplified frequency dependence in both $R_{L}$ and in $E_{L}$ (see "Forward modeling" section). The constant phase model has only one parameter, $G$, that can amplify frequency dependence. Hence when inversely modeling these data, $G$ increases but this has nothing to do with the change in tissue properties [66]. Hence while low frequency FOT data itself is highly sensitive to the occurrence of heterogeneous constriction, inverse modeling approaches cannot distinguish heterogeneous constriction from changes in tissue viscoelasticity from these data.

\section{Forward modeling}

A powerful approach to assess how constriction patterns and tissue properties can impact lung function is to use a forward model to predict impedances at various frequency ranges and interpret the results obtained from inverse modeling. Here, a baseline airway tree was generated from morphometric studies on the lungs by Horsfield et al. [67, 68]. Airway wall properties were incorporated which assumed that the wall consists of both soft tissue and cartilage with a wall thickness, $h$, as a function of airway generation dependent on airway radius, $r_{c}$, and cross-sectional wall area, WA, described below [52, 54, 69, 70].

$$
h=\sqrt{r_{c}^{2}+\frac{W A}{\pi}}-r_{c}
$$

Constriction was applied to peripheral airways with diameters $<0.4 \mathrm{~mm}$, scaled to FRC (above a Horsfield order of 6), by varying means, $\mu$, and coefficients of variation, $C V$, in the reduction of airway diameters based on a Gaussian distribution. At baseline from 0.1 to $1 \mathrm{~Hz}$, $R_{L}$ exhibited a mild frequency dependent decrease followed by a plateau from 2 to $5 \mathrm{~Hz}$ while $E_{L}$ exhibited a mild frequency dependent over the same frequencies followed by a decrease due to airway inertance that becomes more dominant at higher frequencies (Fig. 2) [54]. These findings were consistent with the notion of viscoelastic tissue properties residing over the lower frequency ranges.

Homogeneous constriction (varying $\mu$ with minimal changes in $C V$ ) resulted in uniform increase in $R_{L}$ at all frequencies without a noticeable increase in $E_{L}$. In striking contrast, heterogeneous constriction (varying $C V$ with minimal changes in $\mu$ ) resulted in a substantial frequency dependence with a frequency dependent decrease in $R_{L}$ and a frequency dependent increase in $E_{L}$ mostly taking place at frequencies $<2 \mathrm{~Hz}$. Here, while the net increase of $R_{L}$ at $4 \mathrm{~Hz}$ was far lower than during homogeneous constriction with a much higher mean reduction of airway diameter, the increase in $R_{L}$ and $E_{L}$ at typical breathing rates was much larger at spontaneous breathing frequencies. In other words, heterogeneous constriction serves to amplify the reduction in mechanical and ventilation lung function from that predicted by the average reduction in airway diameter across the whole tree. This same behavior is observed when expanded to a three-dimensional geometric model of the lung [41]. Moreover, when a few $(\sim 10 \%)$ of these peripheral airways are closed but distributed in a heterogeneous fashion, both $R_{L}$ and $E_{L}$ undergo substantial elevations with more frequency dependence when heterogeneous constriction is applied [52, 

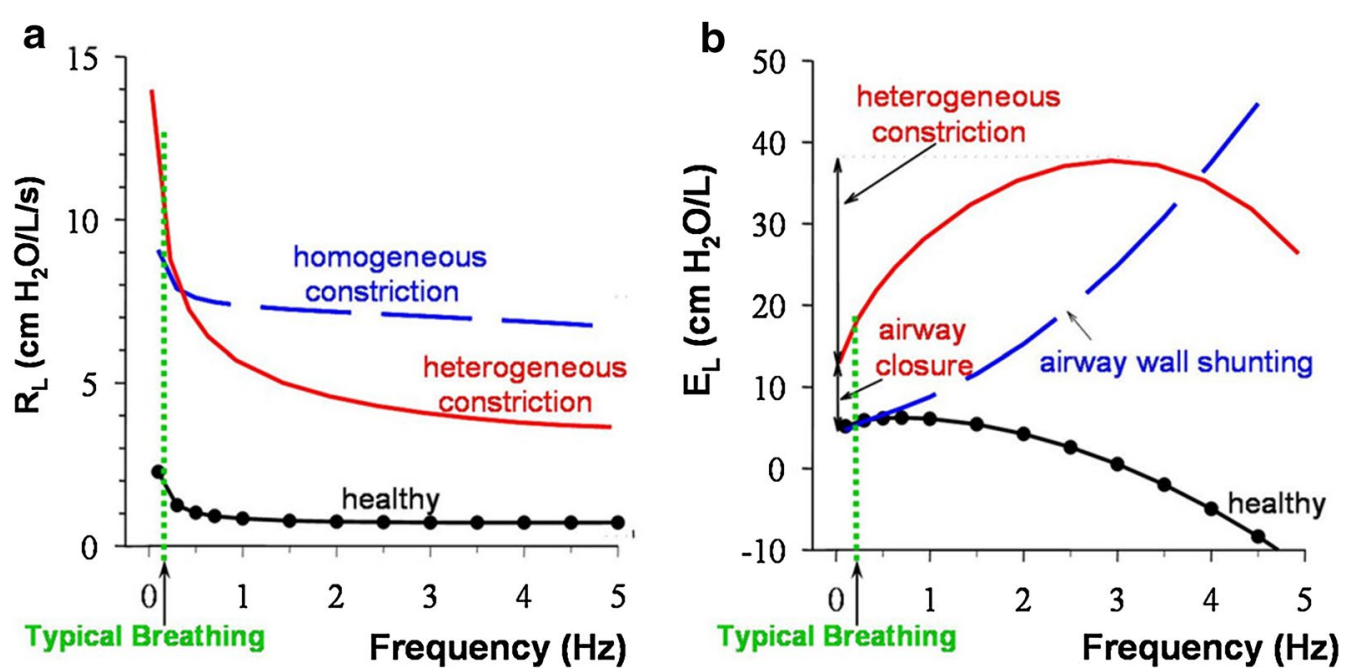

Fig. 2 Modeled lung resistance (a) and lung elastance (b) derived from an airway tree model. Homogeneous constriction leads to a uniform elevation in $R_{L}$ and significant shunting into the compliant central airways presenting as a progressive increase in $E_{L}$ with frequency. Heterogeneous constriction leads to an increased frequency dependence in both $R_{L}$ and $E_{L}$ (reproduced with permission from [19])

54]. In addition, there can also be a significant increase in $E_{L}$ at higher frequencies believed to be secondary to pressures shunting across the walls of the central airway [15]. Together, these findings support the notion of heterogeneous airway closures occurring mainly at the lung periphery [54]. When translated to the measured data, the frequency dependent behavior of $R_{L}$ and $E_{L}$ provide rich physiological insights on mechanisms of dysfunction that may be occurring in asthmatic subjects (Fig. 3) [18, 19, 23].

\section{Heterogeneity of lung ventilation}

By synthesizing structurally consistent forward models with data from oscillatory lung mechanics at low frequencies, we can detect that indeed airways in asthmatics constrict heterogeneously. We further show that the frequency dependence and heterogeneity seem to worsen with disease severity [19] and that, consequently, mechanical lung function rapidly declines which greatly amplifies the work of breathing. What we cannot tell from such data is explicit insight as to physically where
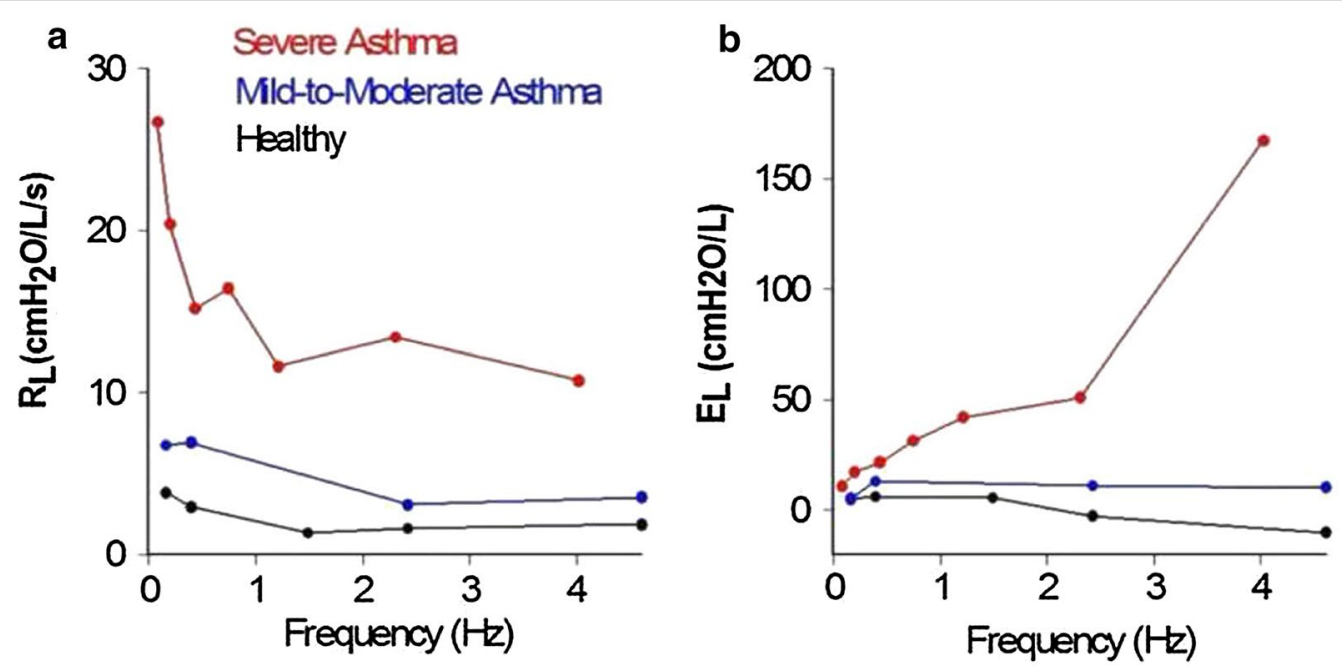

Fig. 3 Measured lung resistance (a) and lung elastance (b) over a wide array of frequencies using an OVW technique in healthy, mild-to-moderate asthma, and severe asthma. With increasing severity of disease, there is more frequency dependence in both $R_{L}$ and $E_{L}$ with significant shunting at high frequencies apparent in $\mathrm{E}_{\mathrm{L}}$ (adapted with permission from [19]) 
and to what degree the ventilation distribution has been degraded. Moreover, we cannot quantify ventilation distributions from mechanical heterogeneity alone and whether the degree of ventilation degradation can lead to amplified mismatches in perfusion and eventually the ability to maintain proper blood gases.

\section{Multiple breath nitrogen washout}

Multiple breath nitrogen $\left(\mathrm{N}_{2}\right)$ washout $(\mathrm{MBNW})$ is a non-invasive approach in the quantitative assessment of ventilation heterogeneity [71-79]. The technique allows prediction of two types of gas transport in the periphery, one that is diffusion-convection-dependent $\left(S_{\text {acin }}\right)$ and one that is convection-dependent $\left(S_{\text {cond }}\right)$, based on the pattern of $\mathrm{N}_{2}$ washout from the lung during tidal breathing of $100 \%$ oxygen [80]. $S_{\text {acin }}$ and $S_{\text {cond }}$ are calculated slopes that reflect the degree of acinar and conductive airway heterogeneity, respectively. Increases in $S_{\text {acin }}$ and $S_{\text {cond }}$ can be found following bronchoprovocation by methacholine in both healthy and asthmatic subjects $[72,78]$. A lung clearance index (LCI) has been another parameter also used to quantify the degree of ventilation heterogeneity. Although LCI has been found to be correlated to $S_{\text {acin }}$ and $S_{\text {cond }}$, its utility and interpretation is still limited [79] since it is a bulk index of reduced ventilation efficiency over the entire lung and not an explicit index of heterogeneity of ventilation. Applying indices of $S_{\text {acin }}$ and $S_{\text {cond }}$, the degree of ventilation heterogeneity at baseline has been found to be linked to the degree of AHR, a hallmark feature of asthma, and can also be used as a predictor of asthma control [71, 73-76]. However, the technique does not maintain any spatial nor specific anatomic regional information. MBNW can only partition the lungs into two main regions: a more central conductive airway region and a more peripheral acinar region. In addition, there were questions of whether the technique can be used to detect poorly ventilated to completely non-ventilated areas of the lungs given findings from recent modeling studies [78].
Hyperpolarized helium-3 magnetic resonance imaging $\mathrm{HP}{ }^{3} \mathrm{He} \mathrm{MRI}$ is a novel imaging modality that directly renders ventilated areas in the lungs through inhalation of a noble gas mixture. While normal healthy lungs tend to exhibit a homogenously distributed pattern of ventilation, diseased lungs, such as in asthma, tend to exhibit patchy areas of ventilation defects (very low levels of HP ${ }^{3} \mathrm{He}$ ) distributed heterogeneously throughout the lungs (Fig. 4) [27-37, 81]. The number and size of ventilation defects have been found to be correlated to spirometry with how the gas redistributes in the lung to be related to asthma severity $[82,83]$. A substantial number $(\sim 75 \%)$ of these ventilation defects persisted or recurred at the same location, and most ( 71\%) did not change in size $[29,30,80]$ although new ones can occur as well over time. Original analysis of these images for assessing ventilation defects were subjective at best, while more recently we have seen the emergence of quantitative approaches [28-30]. One approach has been calculating a $C V$ of signal intensity within these images as a surrogate for ventilation heterogeneity [27, 32, 37]. Unsurprisingly, ventilation heterogeneity (i.e., the $C V$ ) was found to increase following bronchoconstriction with methacholine $[27,32,37]$. Additionally, the degree of ventilation heterogeneity was also found to be correlated with measurements of lung mechanics [32], further reinforcing the relationship with asthma severity found from prior qualitative studies which compared measurements to spirometry [28]. Moreover, concordant with previous findings using MBNW, the degree of ventilation heterogeneity at baseline was also found to be correlated to AHR (Fig. 5) [32]. This finding has very important implications: (1) whether underlying airway conditions prior to bronchoprovocation is a critical factor leading to increased AHR and (2) whether a preexisting abnormal pattern of ventilation (i.e., heterogeneity) will enhance the subsequent degradation in lung function consistent with instability mechanisms proposed through modeling studies $[39,84]$.

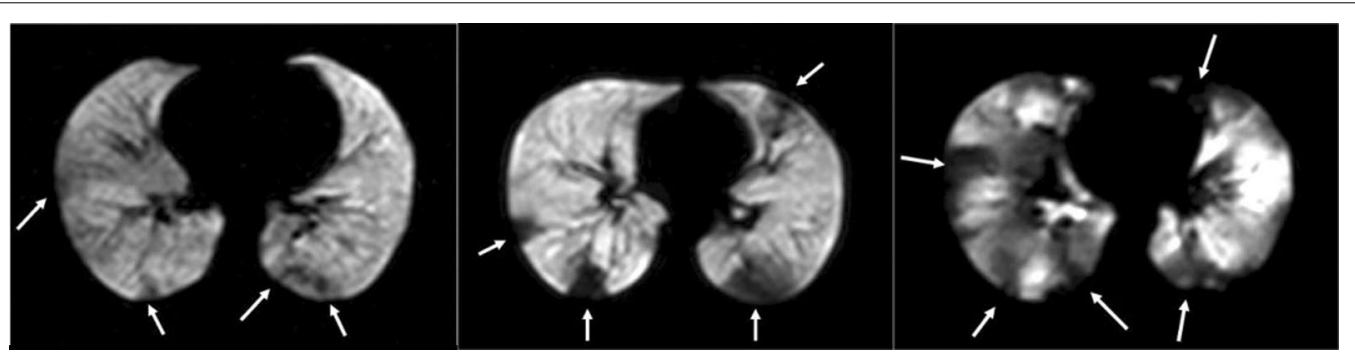

Fig. 4 Hyperpolarized helium-3 MRI axial slice of a mild asthmatic (left panel), a moderate asthmatic (middle panel), and a severe asthmatic (right panel). As depicted by the arrows, increasing severity of disease is associated with increasing ventilation defects and ventilation heterogeneity (reproduced with permission from [28]) 


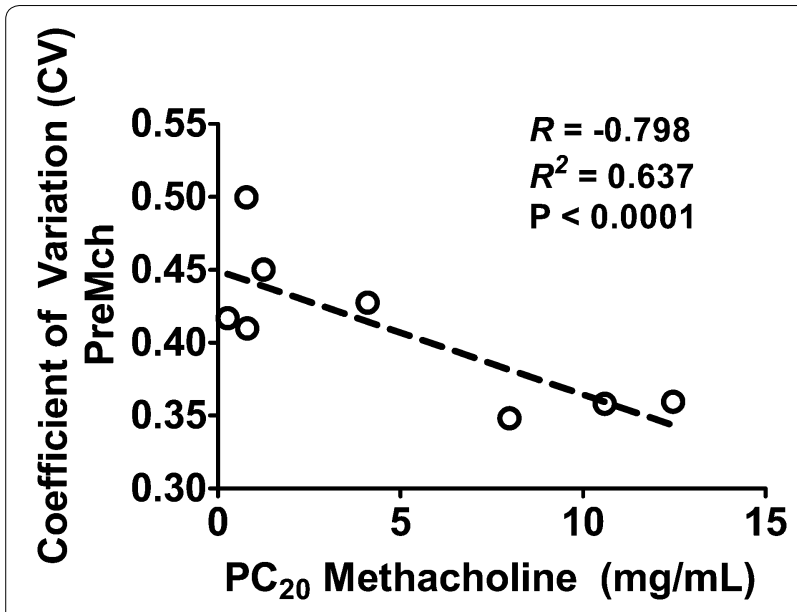

Fig. 5 Relationship between baseline CV and AHR. Here, AHR was measured by the concentration of methacholine that elicits a $20 \%$ decrease in the subject's $F E V_{1}$ compared to baseline $\left(\mathrm{PC}_{20}\right)$ dose. Lower $\mathrm{PC}_{20}$ doses denote higher degree of AHR. Note that there is a negative correlation between the baseline levels of ventilation heterogeneity, (i.e., the $\mathrm{CV}$ ), and the $\mathrm{PC}_{20}$ dose in the asthmatic subjects (reproduced with permission from [32])

\section{Image functional modeling to distill specific anatomic airway origins of reduced function}

To probe airway conditions linking structural changes in the lungs to measurements of mechanical function, an approach termed image functional modeling (IFM) was devised. The method employs a three-dimensional airway tree model based on a volume filling algorithm developed by Tawhai et al. [22, 27, 85]. Parameters within the model include dimensions and location of all airways inclusive of their branching angles obtained from previous morphometric studies with human airways $[68,85]$. A stack-based algorithm traverses the airway tree and determines the highest branch to designate for closure to reproduce the ventilation defect in precise anatomic locations of the model that correspond to the anatomic locations of the image. Each branch within the airway tree is modeled assuming laminar flow in a compliant walled tube and hence requires a distinct flow resistance and inertance partitioned via a shunt airway wall compliance with each parameter for an airway branch a function of its length, diameter and wall material properties (Eq. 13). The terminal airways are then connected to a gas compression associated with the alveolar gas in parallel with a constant-phase tissue model all scaled to the appropriate volume. Impedance of the entire tree as well as ventilation distribution to all alveolar regions can be calculated by the appropriate series and parallel calculations also through a stack-based algorithm. All airway diameters are scaled to FRC, and the subsequent lung volume at FRC is distributed evenly among the terminal alveolar units.

One can synthesize these forward models with imaging and FOT data taken in asthmatics after inducing airway constriction by administering an airway smooth muscle agonist (i.e., methacholine). Heterogeneous constriction patterns can be imposed onto the airway tree to simulate oscillatory lung mechanics (Fig. 6) to best match measured frequency dependence of $R_{L}$ and $E_{L}$ determined by Eq. 11 [41, 52-54]. Simultaneously, one can overlay data from ventilation imaging of the lung obtained from PET $[21,22]$ and HP ${ }^{3} \mathrm{He}$ MRI [27] onto the 3D anatomic

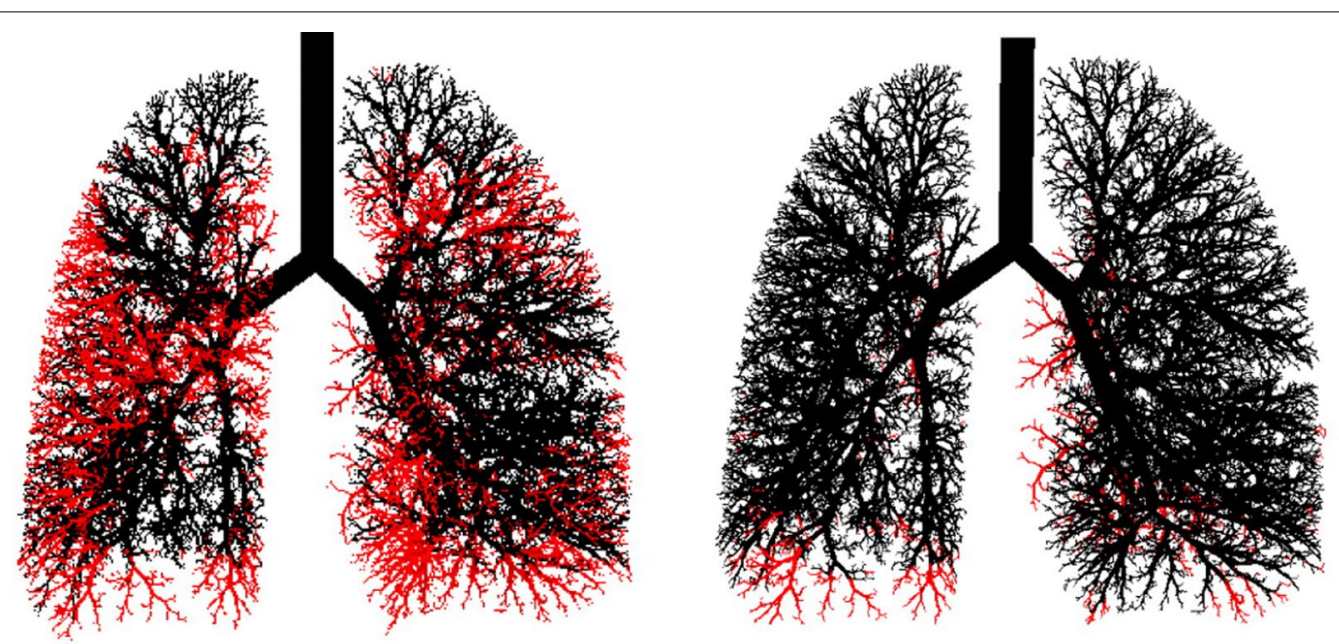

Fig. 6 A model airway tree for an asthmatic subjects following bronchoconstriction with methacholine (left) and following bronchodilation with albuterol (right). Open ventilated airways are depicted in black with closed nonventilated airways depicted in red. Note that following bronchodilation, most, but not all, of the airways recover (reproduced with permission from [27]) 
airway tree and then impose on the model the appropriate anatomic locations of the sites of airway closures and/or ventilation defects to match the imaging data (Fig. 7). This is accomplished by first scaling the airway tree model to the volume defined by ventilation imaging followed by subsequent mapping of the terminal alveolar units to each ventilation defect. What is unique and ideal about the approach is that it isolates airway conditions that requires simultaneous matching of two functional measures for heterogeneity in lung mechanics and in ventilation.

It was found that for mild to moderate asthmatic subjects, one cannot match both data sets simultaneously by only constricting or closing larger airways. Doing so either caused ventilation defects in model locations that did not occur in the actual imaging data, impedance increases inconsistent with the data, or both. The only way to match both data simultaneously required heterogeneous closures of small peripheral airways $(<2 \mathrm{~mm})$ in the airway tree $[22,27]$. The airways leading to these ventilation defects did not need to be completely closed but rather constricted by $\sim 70 \%$ of their baseline diameters [27]. This implies that although these airways may be ventilated, they operate with a time constant such that they are functionally closed in gas exchange [27]. Moreover, severe constriction of the terminal alveolar units and airways leading to these ventilation defects were not sufficient to explain the degree of mechanical dysfunction during bronchoconstriction [21]. Although anatomically consistent airway tree models have been designed to explain ventilation defects via large airway closures, their significance and mechanical implications are still unclear [40]. It has been speculated that with more severe asthma, airway closures may occur in larger airways

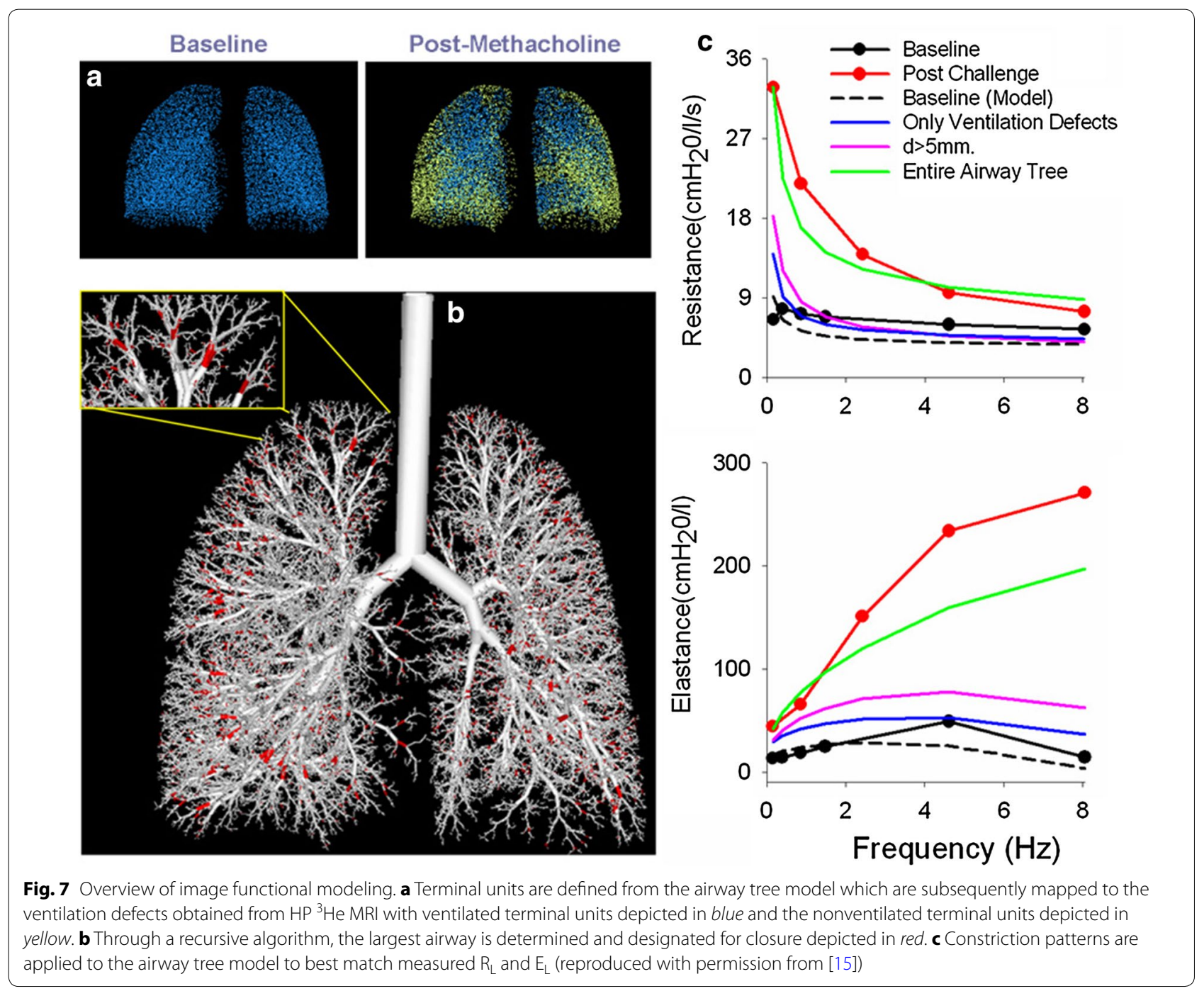


( $\geq 2 \mathrm{~mm}$ ) due to airway remodeling and inflammation. Moreover, computational modeling studies have suggested that there may indeed be some coupling between the constriction of larger airways and smaller airways leading to heterogeneous clustering of ventilation defects [84].

\section{Summary and conclusion}

Over the past few decades substantial evidence has emerged that heterogeneous constriction, particularly in the peripheral airways, are key contributors to measures of reduced mechanical and ventilation function in lung disease $[11,86]$. Previously, it was believed that due to their extensive parallel nature, these areas in the lung represented the silent zone with negligible resistive contributions to the total lung resistance. This is true for the healthy lung. However, advances in FOT and imaging have illustrated an intrinsic degree of heterogeneity that affects both large and small airways. The FOT captures the impact via the nature of a parallel tree structure to dramatically amplify the frequency dependent behavior of mechanical indices. This is accomplished in a fashion that would amplify $R_{L}$ and $E_{L}$ to a much greater extent due to network topology than one would predict by knowing the average diameter reduction of any single airway. Such insights become more prevalent using inverse and forward modeling schemes. More recently, imaging has evolved to enable visualization of ventilation in the lungs. Unsurprisingly, this same phenomenon of heterogeneity present in lung mechanics has also been prevalent in the pattern of ventilation and has been found to be associated with AHR that occurs in asthma. Indeed non-invasive imaging has great potential to assess the likelihood and degree of AHR (i.e., if there are baseline ventilation defects) and for tracking the efficacy of therapy to impact reactivity if it can remodel the airways to reduce baseline heterogeneity. Through combining measurements of mechanics and advances in imaging, we now have a powerful tool to explain how these structural heterogeneous changes lead to the dysfunction seen in asthma.

\footnotetext{
Abbreviations

AHR: airway hyperresponsiveness; $Q_{a 0}$ : flow at airway opening; $P_{a 0}$ : pressure at airway opening; $R_{L}$ : lung resistance; $E_{L}$ : lung elastance; FOT: forced oscillation technique; HP ${ }^{3} \mathrm{He}$ MRl: hyperpolarized helium-3 magnetic resonance imaging; $P_{c w}$ : pressure at the chest wall; $Z_{t r}$ : transfer impedance; $Z_{i n}$ : input impedance; $Z_{r s}$ : respiratory system impedance; $Z_{L}$ : lung impedance; $\omega$ : frequency, in radians; $R_{r s}$ : respiratory system resistance; $X_{r s}$ : respiratory system reactance; $Z_{L}$ : lung impedance; $P_{e s}$ : intraesophageal pressure; $P_{i p}$ : intrapleural pressure; $P_{t p}$ : transpulmonaty pressure; FRC: functional residual capacity; OVW: optimal ventilation waveform; $E_{r s}$ : respiratory system elastance; $I_{r s}$ : respiratory system inertance; $\omega_{0}$ : resonant frequency; $R_{a w}$ : airway resistance; $I_{a w}$ : airway inertance; $R_{t ;}$ : tissue resistance; $l_{t ;}$ tissue inertance; $C_{t ;}$ tissue compliance; $C_{g}$ : gas compliance; $Z_{a w}$ : airway impedance; $Z_{t i}$ : tissue impedance; $G$ : coefficient of tissue damping; $H$ : coefficient of tissue elastance; aa: constant phase parameter;
}

$h$ : wall thickness; $r$ : airway radius; WA: airway cross-sectional wall area; $\mu$ : mean; CV: coefficient of variation; MBNW: multiple breath nitrogen washout; $N_{2}$ : nitrogen; $S_{\text {acin: }}$ : diffusion-convection-dependent gas transport; $S_{\text {cond: }}$ : convection-dependent gas transport; LCl: lung clearance index; PET: positron emission tomography; IFM: image functional modeling.

\section{Authors' contributions}

$J K L$ drafted the manuscript. JKL and KRL reviewed and edited the manuscript. Both authors read and approved the final manuscript.

\section{Author details \\ ${ }^{1}$ Department of Medicine, University of Massachusetts Medical School, 55 Lake Avenue North, Worcester, MA 01655, USA. ${ }^{2}$ Department of Biomedical Engineering, Boston University, Boston, MA 02215, USA.}

\section{Acknowledgements}

Not applicable.

Competing interests

The authors declare that they have no competing interests.

\section{Availability of data and materials \\ Not applicable.}

\section{Consent for publication}

Not applicable.

\section{Ethics approval and consent to participate}

Not applicable.

Funding

This work did not receive any funding.

\section{Publisher's Note}

Springer Nature remains neutral with regard to jurisdictional claims in published maps and institutional affiliations.

Received: 5 June 2017 Accepted: 26 July 2017

Published online: 03 August 2017

\section{References}

1. Sekiya K, Nakatani E, Fukutomi Y, Kaneda H, likura M, Yoshida M, Takahashi K, Tomii K, Nishikawa M, Kaneko N, Sugino Y, Shinkai M, Ueda T, Tanikawa Y, Shirai T, Hirabayashi M, Aoki T, Kato T, lizuka K, Homma S, Taniguchi M, Tanaka H (2016) Severe or life-threatening asthma exacerbation: patient heterogeneity identified by cluster analysis. Clin Exp Allergy 46(8):1043-1055

2. Fajt ML, Wenzel SE (2015) Asthma phenotypes and the use of biologic medications in asthma and allergic disease: the next steps toward personalized care. J Allergy Clin Immunol 135(2):299-310

3. Koczulla AR, Vogelmeier CF, Garn H, Renz H (2017) New concepts in asthma: clinical phenotypes and pathophysiological mechanisms. Drug Discov Today 22(2):388-396

4. Bønnelykke K, Ober C (2016) Leveraging gene-environment interactions and endotypes for asthma gene discovery. J Allergy Clin Immunol 137(3):667-679

5. Thompson MD, Capra V, Clunes MT, Rovati GE, Stankova J, Maj MC, Duffy DL (2016) Cysteinyl leukotrienes pathway genes, atopic asthma and drug response: from population isolates to large genome-wide association studies. Front Pharmacol 7:299

6. Maagdenberg H, Vijverberg SJ, Bierings MB, Carleton BC, Arets HG, de Boer A, Maitland-van der Zee AH (2016) Pharmacogenomics in pediatric patients: towards personalized medicine. Paediatr Drugs 18(4):251-260

7. Repapi E, Sayers I, Wain LV, Burton PR, Johnson T, Obeidat M, Zhao JH, Ramasamy A, Zhai G, Vitart V, Huffman JE, Igl W, Albrecht E, Deloukas P, Henderson J, Granell R, McArdle WL, Rudnicka AR, Wellcome Trust Case Control Consortium, Barroso I, Loos RJ, Wareham NJ, Mustelin L, 
Rantanen T, Surakka I, Imboden M, Wichmann HE, Grkovic I, Jankovic S, Zgaga L, Hartikainen AL, Peltonen L, Gyllensten U, Johansson A, Zaboli G, Campbell H, Wild SH, Wilson JF, Gläser S, Homuth G, Völzke H, Mangino M, Soranzo N, Spector TD, Polasek O, Rudan I, Wright AF, Heliövaara M, Ripatti S, Pouta A, Naluai AT, Olin AC, Torén K, Cooper MN, James AL, Palmer LJ, Hingorani AD, Wannamethee SG, Whincup PH, Smith GD, Ebrahim S, McKeever TM, Pavord ID, MacLeod AK, Morris AD, Porteous DJ, Cooper C, Dennison E, Shaheen S, Karrasch S, Schnabel E, Schulz H, Grallert H, Bouatia-Naji N, Delplanque J, Froguel P, Blakey JD, NSHD Respiratory Study Team, Britton JR, Morris RW, Holloway JW, Lawlor DA, Hui J, Nyberg F, Jarvelin MR, Jackson C, Kähönen M, Kaprio J, Probst-Hensch NM, Koch B, Hayward C, Evans DM, Elliott P, Strachan DP, Hall IP, Tobin MD (2010) Genome-wide association study identifies five loci associated with lung function. Nat Genet 42(1):36-44

8. Li X, Howard TD, Moore WC, Ampleford EJ, Li H, Busse WW, Calhoun WJ, Castro M, Chung KF, Erzurum SC, Fitzpatrick AM, Gaston B, Israel E, Jarjour NN, Teague WG, Wenzel SE, Peters SP, Hawkins GA, Bleecker ER, Meyers DA (2011) Importance of hedgehog interacting protein and other lung function genes in asthma. J Allergy Clin Immunol 127(6):1457-1465

9. Hawkins GA, Robinson MB, Hastie AT, Li X, Li H, Moore WC, Howard TD, Busse WW, Erzurum SC, Wenzel SE, Peters SP, Meyers DA, Bleecker ER, National Heart, Lung, and Blood Institute-sponsored Severe Asthma Research Program (SARP) (2012) The IL6R variation Asp (358) Ala is a potential modifier of lung function in subjects with asthma. J Allergy Clin Immunol 130(2):510-515

10. Hancock DB, Eijgelsheim M, Wilk JB, Gharib SA, Loehr LR, Marciante KD, Franceschini N, van Durme YM, Chen TH, Barr RG, Schabath MB, Couper DJ, Brusselle GG, Psaty BM, van Duijn CM, Rotter Jl, Uitterlinden AG, Hofman A, Punjabi NM, Rivadeneira F, Morrison AC, Enright PL, North KE, Heckbert SR, Lumley T, Stricker BH, O'Connor GT, London SJ (2010) Meta-analyses of genome-wide association studies identify multiple loci associated with pulmonary function. Nat Genet 42(1):45-52

11. Bates JHT, Lutchen KR (2005) The interface between measurement and modeling of peripheral lung mechanics. Respir Physiol Neurobiol 148:153-164

12. Bhatawadekar SA, Hernandez P, Maksym GN (2015) Oscillatory mechanics in asthma: emphasis on airway variability and heterogeneity. Crit Rev Biomed Eng 43(2-3):97-130

13. Dubois AB, Brody AW, Lewis DH, Burgess BF Jr (1956) Oscillation mechanics of lungs and chest in man. J Appl Physiol 8:587-594

14. Kaczka SW, Dellacá RL (2011) Oscillation mechanics of the respiratory system: applications to lung disease. Crit Rev Biomed Eng 39(4):337-359

15. LaPrad AS, Lutchen KR (2008) Respiratory impedance measurements for assessment of lung mechanics: focus on asthma. Respir Physiol Neurobiol 163:64-73

16. Oostveen E, MacLeod D, Lorino H, Farre R, Hantos Z, Desager K, Marchal F (2003) The forced oscillation technique in clinical practice: methodology, recommendations and future developments. Eur Respir J 37:264-272

17. Cavalcanti JV, Lopes AJ, Jansen JM, Melo PL (2006) Detection of changes in respiratory mechanics due to increasing degrees of airway obstruction in asthma by the forced oscillation technique. Respir Med 100(12):2207-2219

18. Kaczka DW, Ingenito EP, Suki B, Lutchen KR (1997) Partitioning airway and lung tissue resistances in humans: effects of bronchoconstriction. J Appl Physiol 82:1531-1541

19. Lutchen KR, Jensen $A$, Atileh $H$, Kaczka DW, Israel E, Suki B, Ingenito EP (2001) Airway constriction pattern is a central component of asthma severity: the role of deep inspirations. Am J Respir Crit Care Med 164(2):207-215

20. Rigau J, Burgoes F, Hernandez C, Roca J, Navajas D, Farre R (2003) Unsupervised self-testing of airway obstruction by forced oscillation at the patient's home. Eur Respir J 22:668-671

21. Tgavalekos NT, Musch G, Harris RS, Vidal Melo MF, Winkler T, Schroeder T, Callahan R, Lutchen KR, Venegas JG (2007) Relationship between airway narrowing, patchy ventilation and lung mechanics in asthmatics. Eur Respir J 29:1174-1181

22. Tgavalekos NT, Tawhai M, Harris RS, Musch G, Vidal-Melo M, Venegas JG, Lutchen KR (2005) Identifying airways responsible for heterogeneous ventilation and mechanical dysfunction in asthma: an image functional modeling approach. J Appl Physiol 99:2388-2397
23. Kaczka DW, Ingenito EP, Israel E, Lutchen KR (1999) Airway and lung tissue mechanics in asthma. Effects of albuterol. Am J Respir Crit Care Med 159:169-178

24. Oostveen $\mathrm{E}$, Boda $\mathrm{K}$, van der Grinten $\mathrm{CP}$, James AL, Young $\mathrm{S}$, Nieland $\mathrm{H}$, Hantos Z (2013) Respiratory impedance in healthy subjects: baseline values and bronchodilator response. Eur Respir J 42(6):1513-1523

25. Yaegashi M, Yalamanchili VA, Kaza V, Weedon J, Heurich AE, Akerman MJ (2007) The utility of the forced oscillation technique in assessing bronchodilator responsiveness in patients with asthma. Respir Med 101:995-1000

26. Zerah F, Lorino AM, Lorino H, Harf A, Macquin-Mavier I (1995) Forced oscillation technique vs spirometry to assess bronchodilatation in patients with asthma and COPD. Chest 108(1):41-47

27. Campana L, Kenyon J, Zhalehdoust-Sani S, Tzeng YS, Sun Y, Albert M, Lutchen KR (2009) Probing airway conditions governing ventilation defects in asthma via hyperpolarized MRI image functional modeling. J Appl Physiol 106(4):1293-1300

28. de Lange EE, Altes TA, Patrie JT, Gaare JD, Knake JJ, Mugler JP, Platts-Mills TA (2006) Evaluation of asthma with hyperpolarized helium-3 MRI: correlation with clinical severity and spirometry. Chest 130(4):1055-1062

29. de Lange EE, Altes TA, Patrie JT et al (2007) The variability of regional airflow obstruction within the lungs of patients with asthma: assessment with hyperpolarized helium-3 magnetic resonance imaging. J Allergy Clin Immunol 119(5):1072-1078

30. de Lange EE, Altes TA, Patrie JT, Battiston JJ, Juersivich AP, Mugler JP, Platts-Mills TA (2009) Changes in regional airflow obstruction over time in the lungs of patients with asthma: evaluation with ${ }^{3} \mathrm{He}$ MR imaging. Radiology 250(2):567-575

31. Lui JK, LaPrad AS, Parameswaran H, Sun Y, Albert MS, Lutchen KR (2013) Semiautomatic segmentation of ventilated airspaces in healthy and asthmatic subjects using hyperpolarized ${ }^{3} \mathrm{He} \mathrm{MRI}$. Comput Math Methods Med. 2013:624683

32. Lui JK, Parameswaran H, Albert MS, Lutchen KR (2015) Linking ventilation heterogeneity quantified via hyperpolarized ${ }^{3} \mathrm{He}$ MRI to dynamic lung mechanics and airway hyperresponsiveness. PLoS ONE 10(11):e0142738

33. Kauczor HU, Markstaller K, Puderbach M, Lill J, Eberle B, Hanisch G, Grossmann T, Heussel CP, Schreiber W, Thelen M (2001) Volumetry of ventilated airspaces by ${ }^{3} \mathrm{He}$ MRI: preliminary results. Invest Radiol 36(2):110-114

34. Kirby M, Heydarian M, Svenningsen S, Wheatley A, McCormack DG, Etemad-Rezai R, Parraga G (2012) Hyperpolarized ${ }^{3}$ He magnetic resonance functional imaging semiautomated segmentation. Acad Radiol 19:141-152

35. Leary D, Svenningsen S, Guo F, Bhatawadekar S, Parraga G, Maksym GN (2016) Hyperpolarized ${ }^{3} \mathrm{He}$ magnetic resonance imaging ventilation defects in asthma: relationship to airway mechanics. Physiol Rep 4(7):e12761

36. Samee S, Altes T, Powers P, de Lange EE, Knight-Scott J, Rakes G, Mugler JP, Ciambotti JM, Alford BA, Brookeman JR, Platts-Mills TA (2003) Imaging the lungs in asthmatic patients by using hyperpolarized helium-3 magnetic resonance: assessment of response to methacholine and exercise challenge. J Allergy Clin Immunol 111(6):1205-1211

37. Tzeng Y-S, Lutchen K, Albert M (2009) The difference in ventilation heterogeneity between asthmatic and healthy subjects quantified using hyperpolarized ${ }^{3} \mathrm{He}$ MRI. J Appl Physiol 106(3):813-822

38. Bhatawadekar SA, Leary D, Maksym GN (2015) Modelling resistance and reactance with heterogeneous airway narrowing in mild to severe asthma. Can J Physiol Pharmacol 93(3):207-214

39. Leary D, Winkler T, Braune A, Maksym GN (2014) Effects of airway tree asymmetry on the emergence and spatial persistence of ventilation defects. J Appl Physiol 117(4):353-362

40. Mullally W, Betke M, Albert M, Lutchen K (2009) Explaining clustered ventilation defects via a minimal number of airway closure locations. Ann Biomed Eng 37(2):286-300

41. Tgavalekos NT, Venegas JG, Suki B, Lutchen KR (2003) Relation between structure, function, and imaging in a three-dimensional model of the lung. Ann Biomed Eng 31(4):363-373

42. Mead J (1969) Contribution of compliance of airways to frequencydependent behavior of lungs. J Appl Physiol 26(5):670-673

43. Brown NJ, Salome CM, Berend N, Thorpe CW, King GG (2007) Airway distensibility in adults with asthma and healthy adults, measured by forced oscillation technique. Am J Respir Crit Care Med 176(2):129-137 
44. Similowski T, Bates JHT (1991) Two-compartment modelling of respiratory system mechanics at low frequencies: gas redistribution or tissue rheology? Eur Respir J 4:353-358

45. Mount LE (1955) The ventilation flow-resistance and compliance of rat lungs. J Physiol 127(1):157-167

46. Otis AB, McKerrow CB, Bartlett RA, Mead J, Mcllroy MB, Selver-Stone NJ, Radford EP Jr (1956) Mechanical factors in distribution of pulmonary ventilation. J Appl Physiol 8(4):427-443

47. Dellacá RL, Santus P, Aliverti A, Stevenson N, Centanni S, Macklem PT, Pedotti A, Calverley PM (2004) Detection of expiratory flow limitation in COPD using the forced oscillation technique. Eur Respir J 23(2):232-240

48. Dellacá RL, Duffy N, Pompilio PP, Aliverti A, Koulouris NG, Pedotti A, Calverley PM (2007) Expiratory flow limitation detected by forced oscillation and negative expiratory pressure. Eur Respir J 29(2):363-374

49. Hantos Z, Daróczy B, Suki B, Galgóczy G, Csendes T (1986) Forced oscillatory impedance of the respiratory system at low frequencies. J Appl Physiol 60(1):123-132

50. Lutchen KR, Yang K, Kaczka DW, Suki B (1993) Optimal ventilation waveforms for estimating low-frequency respiratory impedance. J Appl Physiol 75(1):478-488

51. Bates JH, Ludwig MS, Sly PD, Brown K, Martin JG, Fredberg JJ (1988) Interrupter resistance elucidated by alveolar pressure measurement in open-chest normal dogs. J Appl Physiol 65:408-414

52. Gillis HL, Lutchen KR (1999) How heterogeneous bronchoconstriction affects ventilation distribution in human lungs: a morphometric model. Ann Biomed Eng 27(1):14-22

53. Gillis HL, Lutchen KR (1999) Airway remodeling in asthma amplifies heterogeneities in smooth muscle shortening causing hyperresponsiveness. J Appl Physiol 86(6):2001-2012

54. Lutchen KR, Gillis H (1997) Relationship between heterogeneous changes in airway morphometry and lung resistance and elastance. J Appl Physiol 83(4):1192-1201

55. Tomalak W, Peslin R, Duvivier C, Gallina C (1993) Optimal frequency range to analyze respiratory transfer impedance with six-element model. J Appl Physiol 75(6):2656-2664

56. Lutchen KR, Everett JR, Jackson AC (1993) Impact of frequency range and input impedance on airway-tissue separation implied from transfer impedance. J Appl Physiol 74(3):1089-1099

57. Ludwig MS, Romero PV, Sly PD, Fredberg JJ, Bates JH (1990) Interpretation of the interrupter resistance after histamine-induced constriction in the dog. J Appl Physiol 68:1651-1656

58. Hantos Z, Daroczy B, Csendes T, Suki B, Nagy S (1990) Modeling of lowfrequency pulmonary impedance in dogs. J Appl Physiol 68(3):849-860

59. Ingenito EP, Davison B, Fredberg JJ (1993) Tissue resistance in the guinea pig at baseline and during methacholine constriction. J Appl Physiol 75(6):2541-2548

60. Tepper R, Sato J, Suki B, Martin JG, Bates JHT (1992) Low-frequency pulmonary impedance in rabbits and its response to inhaled methacholine. J Appl Physiol 73(1):290-295

61. Mount $L$ (1969) The ventilation flow-resistance and compliance of rat lungs. J Appl Physiol 26:670-673

62. Hantos Z, Daroczy B, Suki B, Nagy S, Fredberg JJ (1992) Input impedance and peripheral inhomogeneity of dog lungs. J Appl Physiol 72:168-178

63. Horie T, Hildebrandt J (1971) Dynamic compliance, limit cycles, and static equilibria of excised cat lung. J Appl Physiol 31:423-430

64. Horie T, Hildebrandt J (1972) Volume history, static equilibrium, and dynamic compliance of excised cat lung. J Appl Physiol 33:105-112

65. Horie T, Hildebrandt J (1973) Dependence of lung hysteresis area on tidal volume, duration of ventilation, and history. J Appl Physiol 35(5):596-600

66. Lutchen KR, Hantos Z, Peták F, Adamicza A, Suki B (1996) Airway inhomogeneities contribute to apparent lung tissue mechanics during constriction. J Appl Physiol 80(5):1841-1849
67. Horsfield K, Kemp W, Phillips S (1982) An asymmetrical model of the airway of the dog lung. J Appl Physiol 79:1440-1448

68. Horsfield K, Dart G, Olson DE, Cumming G (1971) Models of the human bronchial tree. J Appl Physiol 31:207-217

69. Suki B, Habib RH, Jackson AC (1993) Wave propagation, input impedance, and wall mechanics of the calf trachea from 16 to 1,600 Hz. J Appl Physiol 75:2755-2766

70. Wiggs BR, Bosken C, Paré PD, James A, Hogg JC (1992) A model of the airway narrowing in asthma and chronic obstructive pulmonary disease. Am Rev Respir Dis 145:1251-1258

71. Hardaker KM, Downie SR, Kermode JA, Berend N, King GG, Salome CM (2013) Ventilation heterogeneity is associated with airway responsiveness in asthma but not COPD. Respir Physiol Neurobiol 189(1):106-111

72. Downie SR, Salome CM, Verbanck S, Thompson BR, Berend N, King GG (2013) Effect of methacholine on peripheral lung mechanics and ventilation heterogeneity in asthma. J Appl Physiol 114(6):770-777

73. Chapman DG, Berend N, Horlyck KR, King GG, Salome CM (2012) Does increased baseline ventilation heterogeneity following chest wall strapping predispose to airway hyperresponsiveness? J Appl Physiol 113(1):25-30

74. Farah CS, King GG, Brown NJ, Peters MJ, Berend N, Salome CM (2012) Ventilation heterogeneity predicts asthma control in adults following inhaled corticosteroid dose titration. J Allergy Clin Immunol 130(1):61-68

75. Hardaker KM, Downie SR, Kermode JA, Farah CS, Brown NJ, Berend N, King GG, Salome CM (2011) Predictors of airway hyperresponsiveness differ between old and young patients with asthma. Chest 139(6):1395-1401

76. Chapman DG, Berend N, King GG, Salome CM (2011) Effect of deep inspiration avoidance on ventilation heterogeneity and airway responsiveness in healthy adults. J Appl Physiol 110(5):1400-1405

77. Downie SR, Salome CM, Verbanck S, Thompson B, Berend N, King GG (2007) Ventilation heterogeneity is a major determinant of airway hyperresponsiveness in asthma, independent of airway inflammation. Thorax 62(8):684-689

78. King GG, Downie SR, Verbanck S, Thorpe CW, Berend N, Salome CM, Thompson B (2005) Effects of methacholine on small airway function measured by forced oscillation technique and multiple breath nitrogen washout in normal subjects. Respir Physiol Neurobiol 148(1-2):165-177

79. Verbanck S, Paiva M, Schuermans D, Hanon S, Vincken W, Van Muylem A (2012) Relationships between the lung clearance index and conductive and acinar ventilation heterogeneity. J Appl Physiol 112(5):782-790

80. Paiva M, Engel LA (1984) Model analysis of gas distribution within human lung acinus. J Appl Physiol Respir Environ Exerc Physiol 56(2):418-425

81. Roos JE, McAdams HP, Kaushik SS, Driehuys B (2015) Hyperpolarized gas MR imaging: technique and applications. Magn Reson Imaging Clin N Am 23(2):217-229

82. Svenningsen S, Guo F, Kirby M, Choy S, Wheatley A, McCormack DG, Parraga G (2014) Pulmonary functional magnetic resonance imaging: asthma temporal-spatial maps. Acad Radiol 21(11):1402-1410

83. Hahn AD, Cadman RV, Sorkness RL, Jarjour NN, Nagle SK, Fain SB (2016) Redistribution of inhaled hyperpolarized ${ }^{3} \mathrm{He}$ gas during breath-hold differs by asthma severity. J Appl Physiol 120(5):526-536

84. Venegas JG, Winkler T, Musch G, Vidal Melo MF, Layfield D, Tgavalekos N, Fischman AJ, Callahan RJ, Bellani G, Harris RS (2005) Self-organized patchiness in asthma as a prelude to catastrophic shifts. Nature 434(7034):777-782

85. Tawhai MH, Pullan AJ, Hunter PJ (2000) Generation of an anatomically based three-dimensional model of the conducting airways. Ann Biomed Eng 28(7):793-802

86. Macklem PT, Mead J (1967) Resistance of central and peripheral airways measured by a retrograde catheter. J Appl Physiol 22:395-401 